\title{
Experiências liminares diante da imagem: breves considerações para a Terapia Ocupacional
}

\section{Threshold experiences before the image: brief considerations for Occupational Therapy}

\author{
Christiane Siegmann $^{1}$, Tania Mara Galli Fonseca ${ }^{2}$
}

http://dx.doi.org/10.11606/issn.2238-6149.v27i3p305-312

\begin{abstract}
Siegmann C, Fonseca TMG. Experiências liminares diante da imagem: breves considerações para a Terapia Ocupacional. Rev Ter Ocup Univ São Paulo. 2016 set.-dez.;27(3):305-12.
\end{abstract}

RESUMO: O diálogo com as artes e com a filosofia constitui um importante dispositivo nas práticas da Terapia Ocupacional. A proposta de uma escrita em composição com imagens é para delas fazer emergir acontecimentos capazes de trazer indícios de um modo de trabalhar em Terapia Ocupacional que, mediado por atividades artísticas, corporais e culturais, busca potencializar a dimensão criativa e expressiva da vida, seguindo outros caminhos que não os da representação e da normatização dos corpos. Uma prática que se constitui como possibilidade para fazer proliferar experiências significativas e comunicáveis, hoje cada vez mais escassas na contemporaneidade. Na compreensão desse saber-fazer, interessa-nos explorar os conceitos de limiar e restos para pensar a noção de "experiência liminar" em Terapia Ocupacional. O presente ensaio deriva de nossa pesquisa de doutoramento que tem como campo empírico as experiências clínicas e de docência do pesquisador-terapeuta abordadas desde suas intersecções com imagens de obras de arte. Quando associamos nossas práticas à arte e às imagens que elas declinam sobre nós, torna-se possível fazer aparições de novas visualidades e legibilidades à Terapia Ocupacional que vão a contrapelo da história oficial biomédica, buscando a consolidação e os desdobramentos de condições tanto de conhecimento quanto de aliados para o acontecimento de uma nova travessia para a profissão.

DESCRITORES: Terapia Ocupacional/métodos; Arte.
Siegmann C, Fonseca TMG. Threshold experiences before the image: brief considerations for Occupational Therapy. Rev Ter Ocup Univ São Paulo. 2016 Sept.-Dec.;27(3):305-12.

ABSTRACT: Within the practices of Occupational Therapy, the dialogue with art and philosophy is an important dispositif. The proposition of writing to images is a compositional strategy which encourages the emergence of events capable of serving as evidence of a mode of working in Occupational Therapy. Mediated by artistic, embodied and cultural activities, looking to increase the potential of creative and expressive dimensions of life, this practice pursues a different line of generating knowledge other than representation and the normalization of bodies. It is a practice that composes itself through the rendering-possible of the proliferation of meaningful and communicable experiences which nowadays are increasingly becoming scarce. In coming to understand this knowing-doing, we are interested in exploring the concepts of the threshold and the remnant which allow us to think the notion of "threshold experience" within Occupational Therapy. This essay is derived from our doctoral research whose empirical field is the clinical and teaching experience of the researcher-therapist at the intersection with images of artworks. When we associate our practices with art and the resulting images that befall us, it becomes possible to bring to light new visualities and legibilities within Occupational Therapy that go against the grain of official biomedical history. In this way, we seek the consolidation and unfolding of conditions not only of knowledge but of new relations towards the possibility of new pathways for the profession.

KEYWORDS: Occupational Therapy/methods; Art.

Elaborado como desdobramento dos estudos de Doutorado no Programa de Pós-Graduação em Psicologia Social e Institucional da UFRGS (em andamento) e da primeira fase da pesquisa "A interface arte, corpo e cultura nos diferentes contextos de atuação do terapeuta ocupacional”, aprovada pelo Comitê de Ética - UFPR (2011 - 2014), que objetivava identificar a consolidação de um território de prática e de pesquisa na Terapia Ocupacional, em âmbito nacional, no qual as linguagens artísticas e culturais têm sido utilizadas como dispositivos de intervenção.

1. Professora Assistente do Departamento de Terapia Ocupacional da Universidade Federal do Paraná - UFPR; Doutoranda do Programa de Pós-Graduação em Psicologia Social e Institucional - UFRGS

2. Professora Titular da Universidade Federal do Rio Grande do Sul - UFRGS; Docente e Pesquisadora do Programa de Pós-Graduação

em Psicologia Social e Institucional - UFRGS e Coordenadora do Grupo de Pesquisa Corpo, Arte e Clínica

Endereço para Correspondência: Prof ${ }^{a}$ Christiane Siegmann - Campus Botânico, Bloco Didático II - UFPR - Av. Lothário Meissner, 632, Jardim Botânico, Curitiba-PR-Brasil CEP: 80210-170. E-mail: siegmann@ufpr.br 


\section{ABERTURA}

$\mathrm{B}$ enjamin ${ }^{1}$ alerta, já no início do século XX, para uma espécie de atrofia das possibilidades de experiência, uma vivência sem experiência, próxima a dos homens que retornavam da Grande Guerra emudecidos, sem conseguir elaborar e transmitir o que haviam sofrido. Nos dias atuais, essa escassez da experiência decorre da convivência cotidiana com diversas expressões da violência, com a impossibilidade efetiva de participação social e o excesso de informações que anestesiam os sentidos. A memória esvaziada de experiências comunicáveis conduz a normatização e a modulação dos modos de existir. Cada vez menos o fora é assimilado como experiência para o sujeito, há um aniquilamento de si, de seus desejos, em prol da manutenção do status quo vigente.

O declínio da experiência desdobra-se como empobrecimento do próprio conhecimento adquirido da prática, restando esta tão simplesmente em um plano alienado e dissociado do pensamento, das ideias e dos conceitos. Trata-se, pois, de assinalar que a experiência (Erfahrung) não deverá se confundir com a experiência sensível, porque esta estaria assegurada no âmbito da vivência (Erlebnis), mas deverá ser definida precisamente pelo salto, pela travessia perigosa de contra efetuar o sensível ao sentido e à linguagem como meio de transmissão e de comunicabilidade entre os homens.

As condições sociais apontadas por Benjamin em seus textos críticos à modernidade têm se intensificado em nossa atualidade, levando-nos a reconhecer a importância da discussão sobre a experiência liminar no âmbito da Terapia Ocupacional que pretendemos enfocar em nosso texto. Experiência liminar corresponde, em nossas considerações, à criação de condições a possíveis deslocamentos entre o vivido e seus sentidos, entre o que se apresenta como consciente e como inconsciente, entre o plano voluntário e involuntário das ações praticadas e vivenciadas. A experiência do limiar implica em uma certa suspensão entre o que está ocorrendo, o já corrido e o que poderá ocorrer. Traz em si um feixe de tempos embaralhados, aponta para algum devir, para um futuro, para alguma passagem com a marca do conhecimento.

Este texto, por conseguinte, se propõe a uma reflexão inicial acerca das experiências liminares em Terapia Ocupacional, destacando dois elementos que as compõem: os conceitos de limiar e restos. Como dispositivo, realiza a análise ensaística de duas imagens de obras de arte selecionadas por sua potência de tornar visíveis as afecções impressas no corpo do pesquisadorterapeuta, a partir de sua experiência profissional na assistência e na docência mediada pelas artes. A proposta de uma escrita em composição com imagens, longe de revelar um sentido intrínseco às obras, é para delas fazer emergir acontecimentos capazes de trazer indícios de um modo de trabalhar que se situa no ponto de articulação entre Terapia Ocupacional, Arte e Filosofia.

Desde nossa inserção no campo da Terapia Ocupacional, sabemos que muitos pesquisadores da área procuraram criar estratégias para reverter o declínio da experiência. Nos anos 1980, a partir da análise crítica de programas terapêuticos ocupacionais centrados na doença e do questionamento de que, em certa medida, suas práticas corroboravam para a manutenção de espaços de segregação nas instituições asilares, terapeutas ocupacionais ampliaram o diálogo com disciplinas das Ciências Sociais e Humanas de modo a reexaminar os modos de pensamento fundantes da profissão. Essa proposição permitiu desencadear o surgimento de um novo paradigma para a profissão, que coexiste com o modelo médico-biológico até os dias atuais².

Entre as novas estratégias de intervenção, encontram-se aquelas que incorporam a arte no processo terapêutico ocupacional, promovendo o deslocamento da clínica para o campo da invenção. Práticas voltadas à dimensão criativa e expressiva da vida, de forma a abrir fissuras nos segmentos duros que compõem o cotidiano, como a submissão da subjetividade e as situações extenuantes às quais estão submetidos os sujeitos assistidos. Trata-se de intervenções que buscam garantir a participação da população atendida em espaços socioculturais e se constituem como possibilidade de enfrentamento aos processos de homogeneização das diferenças ${ }^{3}$. Nessa mudança de paradigma, o diálogo transdisciplinar é incorporado à identidade profissional compondo ações na tessitura "com processos artísticos e criativos, processos socioeducativos em espaços inclusivos, propostas de atenção comunitária e um redimensionamento das relações entre saúde, qualidade de vida e trabalho" (p.85)

Na compreensão desse saber-fazer surgem alguns questionamentos: Como o terapeuta ocupacional pode atuar para fazer proliferar as experiências significativas e as possibilidades de experimentação? Poderia a participação em atividades expressivas constituir-se como possibilidade de vivenciar uma experiência liminar? Essa escrita se propõe a indicar alguns possíveis caminhos para a problematização destas questões. 


\section{INDÍCIOS PARA UM FAZER METODOLÓGICO}

O presente ensaio deriva de nossa pesquisa de doutoramento que tem como campo empírico fragmentos, restos, rememorações do pesquisador-terapeuta sobre sua experiência clínica e de docência, que emergem no encontro com as imagens de obras de arte. Trata-se de uma pesquisa conceitual que, assim como os casos-pensamento ${ }^{(1)}$, considera "os planos intensivos da memória, que pedem passagem no corpo do pesquisador. [...]. Memórias do sujeito nessas ações e sua história, não como obra da razão que o paralisa, mas como um inconsciente plano de intensidades" (p.59) .

Nesta abordagem, as imagens situam-se como possíveis dispositivos para pensar as experiências liminares na Terapia Ocupacional. Trata-se de estabelecer relações com aquilo que a imagem produz em nossos corpos e em nossas práticas profissionais. Sua análise, em composição com as afecções do pesquisador-terapeuta diante da imagem, nos insta a saber: $\mathrm{O}$ que foi possível experimentar a partir da imagem-obra? Que aberturas de pensamento ela produz acerca do saber-fazer profissional? Quais forças transversalizam a obra e nos desacomodam?

A seleção das imagens se constitui uma atitude ético-estética, pois se efetua a partir de um corte, de uma escolha e, também, carrega um senso político na medida em que propõe o embate das forças paradoxais que atravessam os corpos em contato com a obra. No registro imagético, o enunciado entrelaça-se com o visível, fazendo emergir descontinuidades a partir da descrição da imagem. O descontínuo, o desvio, os restos são parte do procedimento de pesquisa e de intervenção.

$\mathrm{Na}$ transversalidade que ocorre nesse processo, quando nos tornamos espectadores de uma imagem, rememorações surgem atualizando aquilo que está sendo vivenciado como uma possibilidade de reinventar o vivido. No vazio estabelecido na interação entre imagem e espectador se processa a subjetividade. Potência de criação da vida. Aquele que olha desterritorializa-se, passa por um processo de percepção e envolvimento com as sutilezas da arte/espaço/tempo registradas na captura de um instante. Ao olhar para a obra o espectador pode interagir, compor-se, transformar-se à medida que estabelece novos agenciamentos com o desejo e as ações cotidianas.

Essa experiência aproxima-se do conceito de limiar apresentado na obra de Benjamin. "O limiar (Schwelle) deve ser rigorosamente diferenciado da fronteira (Grenze).

\footnotetext{
(1) O termo caso-pensamento surge em consonância aos estudos de Deleuze e constitui-se em uma estratégia metodológica apresentada no artigo "Caso-pensamento como estratégia de produção de conhecimento" (Siegmann, Fonseca, 2007)5
}

O limiar é uma zona. Mudança, transição, fluxo estão contidos na palavra schwellen (inchar, intumescer), e a etimologia não deve negligenciar estes significados". (p. $535)^{6}$. As experiências liminares são instantes de vertigem, zonas de aprender a perder-se, ou mesmo, de espera.

Para uma breve aproximação às experiências liminares na Terapia Ocupacional, escolhemos duas imagens de obras de arte que pudessem dar abertura a elementos das práticas mediadas pelas artes: uma fotografia e um documentário. De certo modo, a descrição do método e o desenvolvimento dessa escrita expõem alguns elementos do saber-fazer em Terapia Ocupacional que se quer aqui evidenciar. No entanto, esse modo de proceder "não começa com Adão e Eva, mas com aquilo sobre o que deseja falar; diz o que a respeito lhe ocorre e termina onde sente ter chegado ao fim, não onde nada mais resta a dizer: ocupa, desse modo, um lugar entre os despropósitos" (p.17) ${ }^{7}$. Portanto, esse ensaio não pretende chegar a conclusões ou categorias universais que determinem um modo único de proceder a Terapia Ocupacional que tem nas artes um recurso de cuidado e de intervenção social, sua procura é, justamente, colocar à mostra algumas "das diferentes possibilidades $\mathrm{e}$ camadas ali sedimentadas pela história" (p. 7) .

Procuremos, então, adentrar nos limiares, nas zonas de transição, que podem surgir no encontro das imagens com aquele que olha e se afeta pela obra, de modo a tomar desse encontro a potência para pensar a prática profissional.

\section{IMAGEM-RESTOS}

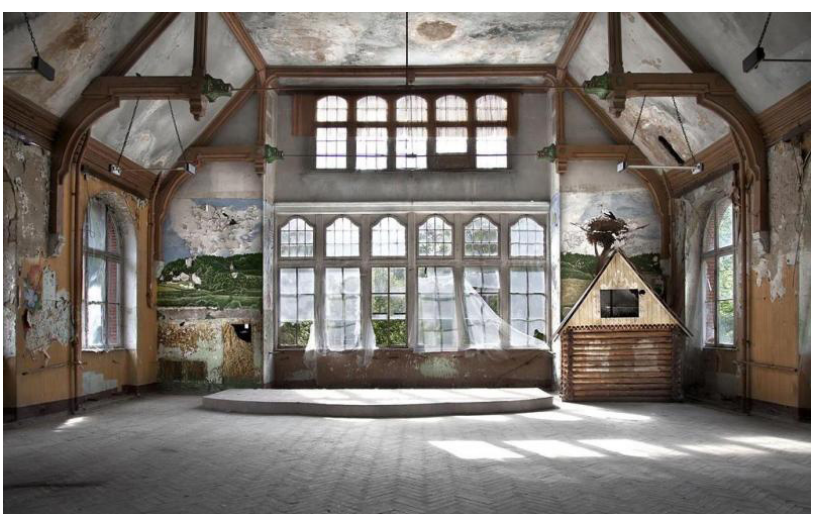

Figura 1 - Beelitz Heilstätten - Hospital em Berlim desativado no Pós II Guerra Mundial - Fotografia de Romy Pocztaruk (2014)

Paredes descascadas, janelas e pisos quebrados de onde emanam odores de urina, mofo, vestígios de sulfa, morfina, violência. Lembranças de cicatrizes de guerra, 
dor, fome, abandono. Restos que sobrevivem ao horror, incapazes de dizer do indizível. Vidas infames. Ruínas. Imagens de um hospital de guerra desativado, que ainda expressam cor, luz, murmúrios e sombras.

Romy Pocztaruk', artista brasileira, expõe fotografias de suas viagens a diferentes regiões do mundo, entre elas imagens de ruínas urbanas do período anterior e posterior à II Guerra Mundial. No movimento de captura da imagem, uma atitude ética e política de escolha se faz presente. Escolha em percorrer lugares esquecidos e de experimentar a produção e a sobrevivência de imagens de momentos históricos marcados pela violência e barbárie. A viagem para Alemanha e a busca pelos 'restos', cinzas de uma memória que não pode ser esquecida como a desse hospital desativado no pós-guerra, faz da fotografia uma imagem-obra, assim como a concepção de imagem trazida por Didi-Huberman na qual

a imagem não é um simples corte praticado no mundo dos aspectos visíveis. É uma impressão, um rastro, um traço visual do tempo que quis tocar, mas também de outros tempos suplementares - fatalmente anacrônicos, heterogêneos entre eles - que, como arte da memória, não pode aglutinar (p.205) $)^{10}$

Sua fotografia é, ainda, objeto de passagem. Passagem de dor, lembranças do horror da guerra, e, simultaneamente, tempo de sobrevivência, de testemunho, de atualização daquilo que ficou silenciado. Uma possibilidade de não esquecer. Imagens nas quais a ausência reclama por vozes daqueles impossibilitados de dizer. Sobreviventes que testemunharam as barbáries dos campos de batalha e, também, aqueles que vivem a experiência-limite na contemporaneidade.

Fotografar de certo modo é ir a contrapelo da história, torná-la imagem, buscar uma revelação para além do que está instituído ou historiografado. Se há rastros, há algo ainda possível de ser olhado ou dito, mas não algo que se vê com os olhos ou se pronuncia em voz alta. Não os vestígios, os fragmentos de memória daquele caos, mas um hiato, o que resta de não enunciável ou arquivável, um testemunho, a "língua na qual o autor consegue dar testemunho de sua incapacidade de falar" (p.161) ${ }^{11}$. Neste sentido, é preciso desconfiar do que se vê, manter os olhos sensíveis a pequenos feixes de luz ou sombra, mantê-los minimamente entreabertos, para que possamos adentrar aos vazios deixados entre a imagem e aquele que vê.

Logo, nunca podemos dizer: não há nada para ver, não há mais nada para ver. Para saber desconfiar do que vemos, devemos saber mais, ver, apesar de tudo. Apesar da destruição, da supressão de todas as coisas. Convém saber olhar como um arqueólogo. E é através [...] de uma interrogação desse tipo - que vemos que as coisas começam a nos olhar a partir de seus espaços soterrados e tempos esboroados. (p.127) $)^{12}$

Ao terapeuta ocupacional a função de um olhar crítico e de uma aceitação de sua própria insuficiência. Perguntar-se: o que vejo nessa fotografia, nessa imagem, nessa história? O que pode ser escutado das vozes silenciadas? Por que vejo dessa forma, com estes significados? Mas perguntar, não para saber como o artista procedeu para captar a imagem, ou o porquê o sujeito vive desse modo, pois não se trata de reconhecer o eu, e sim, os agenciamentos coletivos que possibilitaram este registro e reverberam outros tantos encontros. Buscar, ao captar os murmúrios, uma aproximação ética de narrar histórias de um outro plano ao avesso do que está determinado pelos modos de subjetivação contemporâneos e pela história 'oficial'.

As testemunhas que viveram os horrores das guerras ou que vivem a precariedade dos modos de existência são vidas embrulhadas, soterradas por uma história que privilegia os grandes feitos, os grandes heróis e relata à exaustão um fato na perspectiva dos que venceram. Para Benjamin, os fatos do passado continuam gerando apelo no presente, "pois não somos tocados por um sopro do ar que foi respirado antes? Não existem, nas vozes que escutamos, ecos de vozes que emudeceram? (p. 223)1. A imagem fotográfica expõe, desse modo, a contradição e a realidade de um passado agora atualizado, pois se esta imagem do hospital pode sobreviver é porque há algo político, é o documento de uma época, de uma violência, é a historicidade visível da própria imagem ${ }^{1}$.

A fotografia de um hospital para vítimas de guerra, com suas paredes recobertas por papéis rasgados e com o assoalho corroído por cupins, expõe a brutalidade de uma época, o sofrimento e a dor dos mutilados de guerra, a perda dos familiares que foram lutar para defender sua pátria, o sofrimento dos profissionais ao receberem centenas de soldados sequelados. A vida por um fio. E, paradoxalmente, expõe a luminosidade e a leveza da brisa que adentram os cômodos, expondo a suavidade da natureza desenhada pela paisagem vista através das janelas. Sopro que ventila o espaço, como a casa de boneca que pode nos remeter às brincadeiras de infância e ao lar. Um respiro. Lugar de passagem que são, simultaneamente, entradas e saídas, devires. 
Nessas passagens, na intervenção junto a sujeitos em situação de vulnerabilidade e isolamento social, terapeutas ocupacionais procuram tensionar a lógica da representação e das generalizações da experiência. Buscam, nas contradições do cotidiano e nas relações de poder ali implicadas, ampliar o fazer criativo e expressivo dos sujeitos assistidos de modo que possam expressar a sua voz, ganhar mundo e devires-outros.

\section{IMAGEM-LIMIAR}
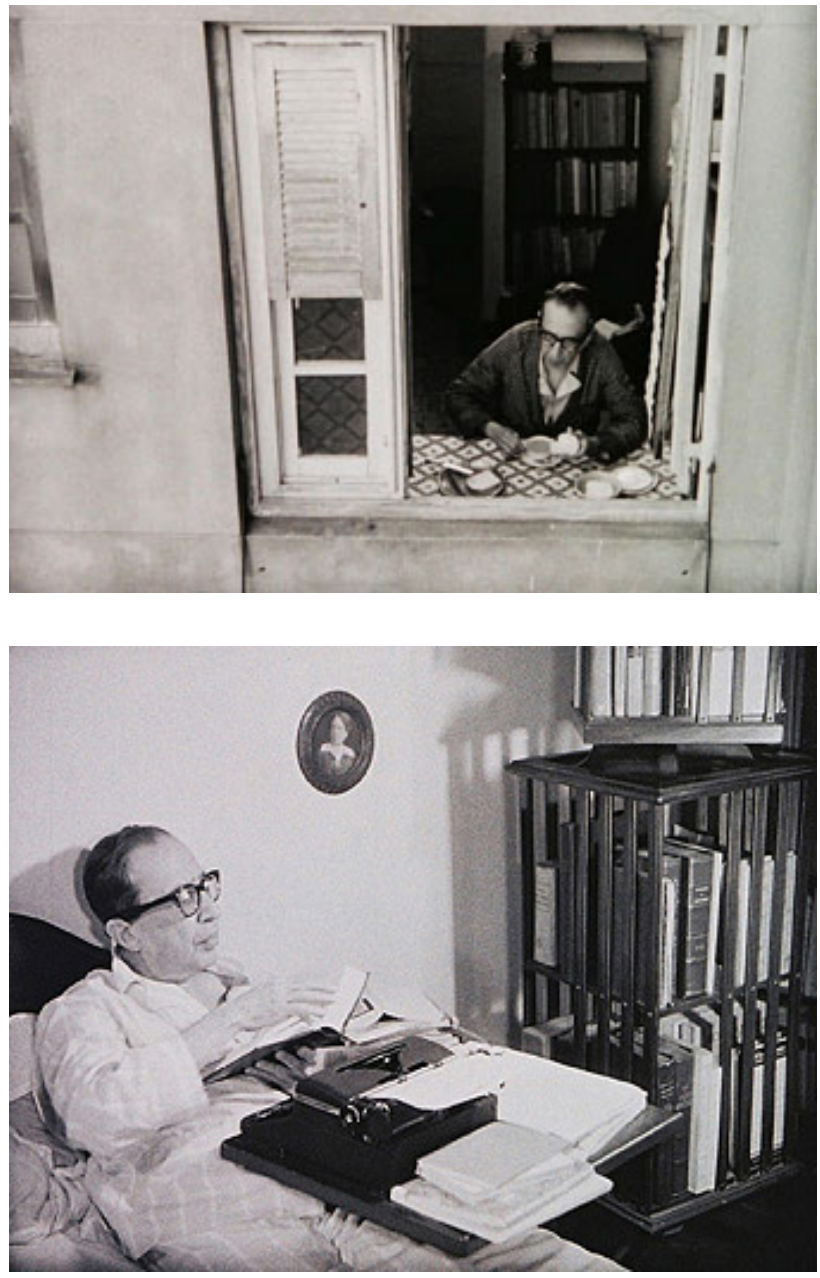

Figuras 2 e 3 - Cenas do documentário O Poeta do Castelo de Joaquim Pedro de Andrade (1959)

Sobre o balcão de lambris envelhecidos e a toalha xadrez, repousam a xícara de café e os pensamentos do poeta. Os livros empoeirados na estante, o velho chambre e o amanhecer conduzem as palavras ao vento ou, distraidamente, as enfileiram na forma de um poema. Sob a janela entreaberta, um tempo em suspensão. E, então, nos perguntamos: pode o registro fílmico de um cotidiano "banal", mesmo que de um ilustre poeta, elevar-se ao estatuto de uma narrativa poética, de uma experiência liminar e constituir-se também como potência clínica?

Tarkovski ${ }^{13}$ nos responderia que sim, mas "esculpir o tempo" seria a condição essencial para o cinema (e a vida) acontecer como arte e produzir sentidos a quem cria e a quem assiste. Joaquim Pedro de Andrade no documentário O Poeta do Castelo ${ }^{14}$ procede este fazer deixando expressar o ritmo próprio de cada fotograma, de cada cena interpretada pelo poeta-personagem. O ritmo cotidiano imaginário mistura-se ao ritmo real da vida de Manuel Bandeira, não só pelo fato do próprio poeta representar a si mesmo, e daí estabelecer o seu ritmo pessoal a cada cena, mas acima de tudo porque o cineasta foi capaz de captar a pressão do tempo existente em cada tomada, em cada gesto cotidiano, suas intensidades e densidades, de "identificar o tipo de movimento do tempo a partir do fluxo do processo vital reproduzido na tomada". (p.143)

E é isso que o cineasta procura respeitar durante a montagem. Neste processo, ele coloca seu estilo, sua forma de perceber o fluxo e a consistência do tempo de cada cena, criando na montagem seu próprio fluxo do tempo, assim como os corpos no encontro-clínico. Objetos, ambientes, gestos, expressões e ritmos constituem a vida do poeta e a vida de todos, compondo uma narrativa singular e comum.

O local onde o poeta guarda a xícara de café, depositada sob uma boleira de vidro, compõe uma cena de tamanha intensidade, que pode levar o espectador a lugares de infância. Lugar onde se podia secretamente guardar nossas coleções de "achados", ou aquele espaço reservado em baixo da árvore de Natal, no qual podíamos espiar as formas dos presentes num jogo de adivinhação, mas, especialmente, aquele espaço-tempo em que tudo entrava em suspensão e poderia vir a ser: o limiar. O momento de hesitação em que permanecíamos parados frente à porta antes da aventura de espiar pela fechadura. Ali onde o tempo pairava no ar, em que apenas o presente podia despertar o passado e seus mistérios e apontar as surpresas por vir.

A essa passagem, às sensações e impressões contraditórias que ficam como marcas em nossos corpos é que podemos nomear como experiências liminares, espaço-tempo intensivo, de presença por inteiro, poucas vezes hoje vivenciadas. Benjamin ${ }^{15}$, ao rememorar sua infância, procura dar visibilidade a essas experiências que nos anos 1930, já como adulto, apresentavam-se esmorecidas. Os lugares de infância denotam a função espacial das experiências liminares para Benjamin, mas 
há também um significado temporal no conceito de limiar. Uma experiência que pode ser percebida naquelas frações de segundos, em que há um torpor e, simultaneamente, vivencia-se uma intensidade, uma duração. Um espaçotempo em que a rememoração e as possibilidades futuras se contraem junto ao presente, com tamanha intensidade capaz de afetar os corpos de forma irreversível. É um momento, que não pode mais retornar ao mesmo, pois singular e único, contém sensações díspares e múltiplas possibilidades. Assim como a experiência do menino Benjamin ao explorar as gavetas na cômoda de seu quarto.

Aquelas meias no fundo da gaveta continham mistérios. Enroladas como uma pequena bolsa escondiamse do menino, que mergulhava a mão até o fundo para apanhar uma entre tantas. Ao trazê-la à luz, desembrulhava a pequena bolsa e comprovava uma verdade enigmática: "que a forma e o conteúdo, que a coberta e o encoberto, que o 'capturado' e a bolsa, eram uma única coisa. Uma única coisa - e, sem dúvida, uma terceira, aquela meia em que ambos haviam se convertido. (p.124) ${ }^{15}$.

Este fragmento autobiográfico compõe o que o autor conceitua como imagens dialéticas que surgem no limiar. Naquele instante, se apreende com o corpo todo algo de indizível e inaudível, pré-individual. $\mathrm{Na}$ hesitação ou no despertar, o corpo é tomado pela passagem de fluxos, intensidades, devires e vive os elementos de uma experiência liminar. O momento da infância em que ainda mantemos o que nos é familiar e de onde se pode "observar sem risco o que se anuncia [...]. 'Dialética' no sentido de o passado estar investido de um sentido futuro" (p. 121) ${ }^{16}$. Nessa contradição de elementos que se fundem, surge um terreno fértil para o desejo. Um lugar que permite pensar. E que tem no aqui e agora, o presente, o passado e o futuro. É o instante efêmero da aprendizagem. O instante do despertar. O princípio da magia, do místico, de conseguir fazer correlações, correspondências, ou seja, de viver a própria experiência.

Passar pelo limiar é a experiência de hesitação do poeta frente à folha em branco na máquina de escrever. Tempo de espera e, também, de passagem onde tudo pode vir a ser, poesia, conto, memórias... enfim, palavras que podem dizer sobre a poética do cotidiano e da própria vida. Ritos de passagem, projetos de vida, possibilidades muitas de agir a partir do limiar sobre e no mundo, mesmo com os limites do corpo ou a privação de direitos que afetam as pessoas em vulnerabilidade. Da poesia menor à poética do cotidiano, da possibilidade de romper com as formas e os limites à possibilidade de experimentação do espaçotempo limiar.
No entanto, "na vida moderna essas transições tornam-se cada vez mais irreconhecíveis e difíceis de vivenciar. Tornamo-nos muito pobres de experiências limiares. $\mathrm{O}$ adormecer talvez seja a única delas que nos restou (E com isso também o despertar) " (p. 535) ${ }^{6}$. A escassez de experiências liminares nos traz ainda uma outra forma de apreensão do conceito de limiar nos dias atuais, um modo mais brutal dessa experiência, e não a sua ausência. Trata-se de um "limiar inchado, caricato, que não é mais lugar de transição, mas perversamente, lugar de detenção, zona de estancamento e de exaustão, como se o avesso da mobilidade trepidante da vida moderna fosse um não poder nunca sair do lugar" (p. 20) ${ }^{17}$. Essa espessura mais densa dos momentos de transição trazem uma experiência de imobilidade, mesmo nos espaços virtuais em que as informações chegam em velocidades inapreensíveis. Essa aceleração cotidiana, em que tudo nos chega incessantemente, nos faz temer experimentar a intensidade da vida, a finitude e a incompletude humana. Um limiar de mortos-vivos, um lugar de bloqueio, anestesiamento e estagnação das possibilidades de vir a ser.

No documentário, o poeta vive um outro tempo. Ao mínimo gesto consegue diferir-se, produzindo intensidade nos fazeres mais cotidianos. Cada cena, cada tomada é, então, impregnada de uma variedade de tempos, o tempo do gesto, o tempo da luminosidade, o tempo do registro fotográfico, o tempo interior de cada fotograma. Esse ritmo temporal pode ser percebido, em toda a sua poética, no ato do poeta em preparar o seu café da manhã. Nas pequenas ações de assoprar a chama do fogão, aguardar com paciência as torradas saltarem da velha torradeira e levantar suavemente a tampa da delicada boleira como que guardasse ali sua maior riqueza, a possibilidade de presentificar uma experiência liminar, no instante mesmo em que sua voz ecoa "sou poeta menor, perdoai! 14".

\section{(DES)ENCERRAMENTO}

As análises empreendidas neste texto fazem-se como próprias a uma zona de limiar que o momento atual oferece ao campo de conhecimento, como a criação de condições tanto de conhecimentos quanto de aliados para o acontecimento de uma travessia. Na escrita dos ensaios, o encontro do pesquisador-terapeuta com as imagens de obras de arte pode constituir-se em um acontecimento, proporcionando brechas, respiros, à medida que, ao destacar-se de um fundo de uniformidade e regularidade, surge como uma diferença, algo não descrito ou previsto a priori $^{18}$. As afecções que surgem desse encontro 
são incapazes de afirmar respostas, mas fundam uma possibilidade de problematizar o saber-fazer profissional. Acontecimento e problematização estão, desse modo, intrinsicamente ligados. Das zonas de apagamento e fragilidade emergem a possibilidade de reconhecimento de si e da incorporação, na prática profissional, de espaços de desacomodação, de "formulação de novas perguntas, em oposição à busca de soluções já determinadas, na medida em que pensar é, de certo modo, destruir as evidências e, simultaneamente criar novas maneiras de ser" (p.118) ${ }^{19}$.

No encontro clínico e na prática docente buscase, por conseguinte, visibilizar os restos, as nuances, aquilo que é singular ao sujeito da ação, não no sentido de inventariar os fatos ocorridos em sua história de vida, mas aquilo que difere, que não é evidente, por isso mesmo singular. 'O que interessa não são os 'grandes' contrastes, e sim os contrastes dialéticos, que frequentemente se confundem com nuances. A partir deles, no entanto, recriase sempre a vida de novo" (p.501)

A postura do espectador em contato com a obra se assemelha ao modo de trabalhar do terapeuta ocupacional implicado com uma atitude estética e política de abertura, estranhamento e problematização. Uma experiência liminar, que justamente, expõe essa abertura às possibilidades de agir sobre o mundo de modos dispares e singulares, abre caminhos outros para os fazeres, para as escolhas, assim como as imagens dialéticas de Benjamin, nas quais uma história, um conto, uma narrativa podem conter uma multiplicidade de possíveis. É, portanto, o

\section{REFERÊNCIAS}

1. Benjamin W. Magia e Técnica, Arte e Política: ensaios sobre literatura e história da cultura. São Paulo: Brasiliense; 1987. (Obras escolhidas I).

2. Castro ED, Lima EMFA, Castiglioni MC, Silva SNP. Análise de atividades: apontamentos para uma reflexão atual. In: De Carlo, MMP, Luzo MCM. Terapia Ocupacional: reabilitação física e contextos hospitalares. São Paulo: Roca; 2004. p.46-73

3. Lima EMA, Inforsato EA, Lima LJC, Castro ED. Ação e criação na interface das artes e da saúde. Rev Ter Ocup Univ São Paulo. 2009;20(3):143-8. http://dx.doi.org/10.11606/issn.2238-6149. v20i3p143-148

4. Moreira AB. Terapia Ocupacional: história crítica e abordagens territoriais/comunitárias. Vita et Sanitas. Trindade. 2008;2(02):79-91. Disponível em: http://www.fugedu.com. br/upload/journals/1/issues/25/public/25-67-PB.pdf resgate dessa experiência que se busca acontecimentalizar na clínica e na formação, não os grandes monumentos, mas aqueles em que seus vestígios são capazes de se atualizar no presente potencializando o fazer e o estar no mundo.

Através dos ensaios procedemos, assim, a rasgadura das imagens-liminares e os possíveis de uma outra maneira de olhar e pensar a Terapia Ocupacional. Os ensaios referem-se, portanto, ao modo, ao como, ao método de analisar e ver, na qual importa misturar conceitos sem perder o elemento sensível, não permanecendo somente nas sensações. Vão além delas porque as conceituam, tal como indica Benjamin ${ }^{1}$. Produção de novas legibilidades e visibilidades, é disso que se trata o nosso intento quando associamos nossas práticas à arte e às imagens que elas declinam sobre nós. Não estamos interessados na arte pela arte. Aqui, as obras se colocam como produtoras de imagens nos sujeitos, como modos de espelhar aquilo que os mesmos podem ver no que os olha, aquilo que é preciso extrair do que os olhos sensíveis veem para transformar, por fim, em imagem.

Talvez o poeta e a fotógrafa possam nos indicar o caminho para que a experiência do limiar novamente faça-se memória viva em nossas histórias. Quiçá seja seguindo a vida por meios expressivos e inventivos, tecendo-a por fragmentos dispares, às vezes contraditórios, assim como as cenas isoladas que ao final compõem a narrativa poética e a história de vida do grande poeta menor.
5. Siegmann C, Fonseca TMG. Caso-pensamento como estratégia de produção de conhecimento. Interface - Comunic. Saúde Educ. 2007;11(21):53-63. http://dx.doi.org/10.1590/S141432832007000100006

6. Benjamin W. Passagens. Belo Horizonte: Editora UFMG; 2006.

7. Adorno TW. Notas de Literatura I. São Paulo: Duas Cidades, Editora 34; 2003.

8. Almeida J. Notas do tradutor. In: Adorno TW. Notas de Literatura I. São Paulo: Duas Cidades, Editora34; 2003.

9. Pocztaruk R. Beelitz. 2013. 1 Fotografia, color, dimensão variável. Disponível em http://romypocz.com/Beelitz

10. Didi-Huberman G. Quando as imagens tocam o real. Pós. Belo Horizonte. 2012;2(4):204-19. 
11. Agamben G. O que resta de Auschwitz: o arquivo e o testemunho (Homo Sacer III). São Paulo: Boitempo; 2008.

12. Didi-Huberman G. Cascas. Rev Serrote. Rio de Janeiro. 2013;(13):99-133.

13. Tarkovski A. Tempo, ritmo e montagem. In: Tarkovski A. Esculpir o tempo. São Paulo: Martins Fonte; 2010. 134-48.

14. Poeta do Castelo. Gênero: Documentário. Direção: Joaquim Pedro de Andrade. Intérprete: Manuel Bandeira. Brasil, 1959. 1 Filme (10 min), son., P\&B, 35mm. Disponível em https://www. youtube.com/watch?v=bJmboP4q53Y Acesso 07/09/2014

15. Benjamin W. Infância em Berlim por volta de 1900. In: Benjamin W. Rua de Mão Única. São Paulo: Brasiliense; 2012. (Obras Escolhidas II)
16. Collomb M. Limiares, aprendizagem e promessa em Infância em Berlim por volta de 1900. In: Otte G, Sedlmayer S, Cornelsen E (org.) Limiares e Passagens em Walter Benjamin. Belo Horizonte: Editora UFMG; 2010 .

17. Gagnebin JM. Entre a vida e a morte. In: Otte G, Sedlmayer S, Cornelsen E (org.) Limiares e Passagens em Walter Benjamin. Belo Horizonte: Editora UFMG; 2010 .

18. Veyne P. Como se escreve a história. 4. ed. Brasília: Editora UNB; 1992.

19. Siegmann C. Pensar e Inventar-se: Terapia Ocupacional como Clínica dos Afectos. Curitiba: Editora CRV; 2011.

Recebido em: 01.10.15

Aceito em: 12.09.16 